\title{
Difficult intravenous access: the Vygon Leadercath as an introducer for wider-bore cannula
}

\author{
Phil Stagg
}

Department of Anaesthetics, Pindara Private Hospital, Benowa, Queensland, Australia

Correspondence to Dr Phil Stagg;

philip.stagg@gmail.com

Accepted 21 November 2021

\section{DESCRIPTION}

Both ultrasound and the Seldinger technique have been shown to improve outcomes during vascular access. $^{1}{ }^{2}$ International guidelines recommend ultrasound-guidance when difficulties are encountered or expected. ${ }^{1}{ }^{3-5}$ However, difficulties still occur, and a broader array of adjuncts is likely to be useful. I would like to recommend a novel technique using the Vygon Arterial Leadercath polyethylene (PE) kit (Vygon, Ecouen, France) as a coaxial introducer for wider-bore cannula, in cases of difficult intravenous access (DIVA).

A 48-year-old man presented for right laparoscopic adrenalectomy and required wide-bore peripheral venous access. Veins were not favourable for direct-puncture. Using ultrasound-guidance, the Vygon Arterial Leadercath 18G (4F) kit (Vygon, Ecouen, France) and aseptic technique, the target vessel was accessed with the $19 \mathrm{G}$ introducer needle. The $0.71 \mathrm{~mm}$ diameter guidewire was inserted and needle removed. The $18 \mathrm{G}, 10 \mathrm{~cm}$ Leadercath was preloaded with a $16 \mathrm{G} 48 \mathrm{~mm}$ BD Insyte cannula (Becton Dickinson, Utah, USA) and inserted as a unit, with the Leadercath acting as a coaxial introducer. The wire and Leadercath were removed, leaving only the conventional wide-bore intravenous cannula in-situ (figures 1 and 2). A 20G (3F) $8 \mathrm{~cm}$ Leadercath can similarly be used to insert an $18 \mathrm{G}$ Insyte cannula (figure 1).

These cannula-over-Leadercath combinations couple seamlessly allowing smooth insertion. Skin incision is not required; however, $48 \mathrm{~mm}$ long cannula are recommended, due to the higher rate of

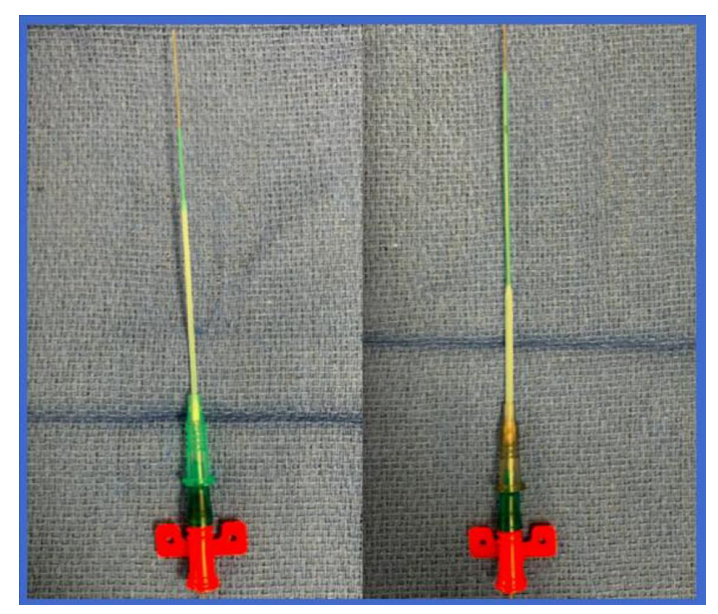

Figure 1 An 18G BD Insyte cannula (Becton Dickinson, Utah, USA) over a 20G Vygon Arterial Leadercath (Vygon, Ecouen, France), and a 16G Insyte cannula over an 18G Vygon Arterial Leadercath.

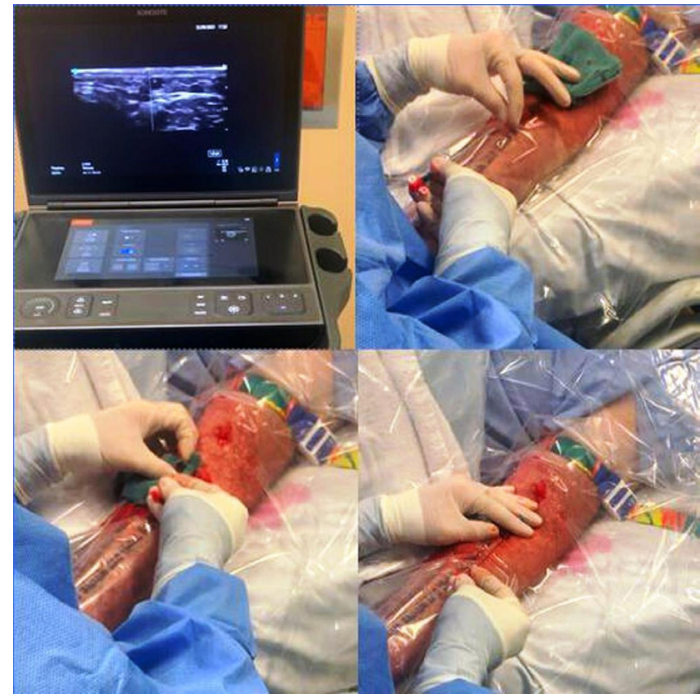

Figure 2 Ultrasound-guided insertion of a 16G Insyte cannula using an $18 \mathrm{G}$ Vygon Arterial Leadercath as a coaxial introducer.

early dislocation when short cannulas are used with ultrasound. ${ }^{6}$ As an adaption, an in-situ 22G Insyte cannula could be easily upsized to an $18 \mathrm{G}$ cannula using the $20 \mathrm{G}$ Leadercath and its $0.53 \mathrm{~mm}$ wire, or an in-situ $20 \mathrm{G}$ Insyte upsized to a $16 \mathrm{G}$ cannula over the $18 \mathrm{G}$ Leadercath and its $0.71 \mathrm{~mm}$ wire for a rapid, two-size cannula upgrade in emergency situations where access is difficult.

The advantage of this cannulation 'lifeline' is primarily combining the benefits of the Seldinger technique with ultrasound-guidance, whist appropriating a relatively ubiquitous device-the Vygon Leadercath, to achieve wide-bore access, in the context of limited availability of equivalent proprietary Seldinger-based intravenous cannulation equipment. Furthermore, some practitioners may be uncomfortable using the Leadercath for standalone access, as the red hub is intended to signify Arterial access, ${ }^{7}$ and may lead to staff confusion. This technique circumvents this problem.

Midline catheters $6-15 \mathrm{~cm}$, or 'long' peripheral intravenous cannulas (PIVCs), have increased in popularity for DIVA of late, and include a limited range of proprietary devices and repurposed Arterial access devices using both the classic and modified-Seldinger technique (integral wire). Devices using the modified Seldinger technique include the AccuCath (Becton Dickinson) and Arrow Quickflash Arterial Catheter (Teleflex, 
Wayne, Pennsylvania, USA). Devices using the classic Seldinger technique include the Vygon Arterial Leadercath and Leaderflex (Vygon).

Studies of these devices have generally demonstrated high insertion success for DIVA, long dwell time and low complication rate ${ }^{8-14}$; however, each has its limitations. Cost, availability, length, lack of pressure rating, off-label use and small gauge are common limiting factors, particularly in resuscitation scenarios where high flow rates are required. As such, these devices are arguably more suited for DIVA in subacute patients requiring maintenance therapy, and a gap in wide-bore solutions still exists.

The above discussion begs the question: Is it time low-cost, wide-bore and purpose-made classic Seldinger/ultrasound cannulation kits were developed? Ideal features would be:

1. Convenient minimalist kits with different gauge options (eg, $12 \mathrm{G}-18 \mathrm{G})$

2. Small-gauge access needle with echogenic tip.

3. A fine wire with floppy tip.

4. A smooth transitioning cannula-over-dilator setup (coaxial introducer), essentially a smaller version of an ARROW Rapid Infusion Catheter (RIC) (Teleflex).

5. Slightly longer than conventional cannula (eg, $50 \mathrm{~mm}$ ) to minimise dislocation, but short enough to maximise flow rate as per the Hagen-Poiseuille Law.

I believe such an option would be a valuable addition to the repertoire for practitioners encountering DIVA. Purposedesigned devices with integral wires such as the AccuCath are a step towards addressing this issue, as they are power injectable and pressure rated to $300 \mathrm{psi}$. However, they have been used with mixed success. ${ }^{12} 1315$ Moreover, sizes (18G-22G) and availability are limited, and ultimately, the classic Seldinger technique has been shown superior to the modified approach. ${ }^{2}$

Finally, the interventional radiology Micropuncture access set (Cook Medical, Bloomington, Indiana, USA) exhibits many of the ideal properties ${ }^{16}$; however, its use in this context is similarly limited due to its longer sheath $(10 \mathrm{~cm})$ that is not designed for fluid administration under pressure. It would, however, serve as a valuable prototype for Seldinger/ultrasound cannulation kits and allows for serial upsizing.

\section{Learning points}

Both ultrasound and the Seldinger technique have been shown to increase success for difficult vascular access.

- The $20 \mathrm{G}$ and $18 \mathrm{G}$ Vygon Arterial Leadercath can be used as a conduit to 'piggyback' in $18 \mathrm{G}$ and $16 \mathrm{G}$ conventional cannula, respectively, due to a seamless fit, representing a novel alternative for situations where wider-bore peripheral access is required.

- Wide-bore (12G-18G), ultrasound-focused Seldinger-based difficult intravenous access kits incorporating a coaxial dilator should be developed for volume resuscitation scenarios.
Future studies could objectively compare efficacy of ultrasound-guided Seldinger cannulation using the above methods versus direct puncture for difficult intravenous access.

Contributors PS treated the patient. PS conceived the idea for the paper. PS authored and edited the manuscript.

Funding The authors have not declared a specific grant for this research from any funding agency in the public, commercial or not-for-profit sectors.

Competing interests None declared.

Patient consent for publication Consent obtained directly from patient(s).

Provenance and peer review Not commissioned; externally peer reviewed.

Case reports provide a valuable learning resource for the scientific community and can indicate areas of interest for future research. They should not be used in isolation to guide treatment choices or public health policy.

\section{ORCID iD}

Phil Stagg http://orcid.org/0000-0002-5723-7776

\section{REFERENCES}

1 Lamperti M, Bodenham AR, Pittiruti M, et al. International evidence-based recommendations on ultrasound-guided vascular access. Intensive Care Med 2012;38:1105-17.

2 Beards SC, Doedens L, Jackson A, et al. A comparison of arterial lines and insertion techniques in critically ill patients. Anaesthesia 1994;49:968-73.

3 Bodenham Chair A, Babu S, Bennett J, et al. Association of anaesthetists of great britain and ireland: safe vascular access 2016. Anaesthesia 2016;71:573-85.

4 Bouaziz H, Zetlaoui PJ, Pierre S, et al. Guidelines on the use of ultrasound guidance for vascular access. Anaesth Crit Care Pain Med 2015;34:65-9.

5 Mbamalu D, Banerjee A. Methods of obtaining peripheral venous access in difficult situations. Postgrad Med J 1999;75:459-62.

6 Keyes LE, Frazee BW, Snoey ER, et al. Ultrasound-guided brachial and basilic vein cannulation in emergency department patients with difficult intravenous access. Ann Emerg Med 1999:34:711-4.

7 Leadercath Arterial: Setting High Standards to Reduce Line Infection. Vygon Product information [Internet], Vygon 5 Rue Adeline 95440 Ecouen, France. Available: https:// cdn.shopify.com/s/files/1/2199/5291/files/Vygon-Leadercath-Arterial_-_MSS.pdf? 11455395844075110207 [Accessed 15 Nov 2021].

8 Fabiani A, Dreas L, Sanson G. Ultrasound-guided deep-arm veins insertion of long peripheral catheters in patients with difficult venous access after cardiac surgery. Heart Lung $2017:$ :46:46-53.

9 Scoppettuolo G, Pittiruti M, Pitoni S, et al. Ultrasound-guided "short" midline catheters for difficult venous access in the emergency department: a retrospective analysis. Int J Emerg Med 2016;9:3

10 Paladini A, Chiaretti A, Sellasie KW, et al. Ultrasound-guided placement of long peripheral cannulas in children over the age of 10 years admitted to the emergency department: a pilot study. BMJ Paediatr Open 2018;2:e000244.

11 Qin KR, Ensor N, Barnes R, et al. Long peripheral catheters for intravenous access in adults and children: a systematic review of the literature. J Vasc Access 2021:22:767-77.

12 Idemoto BK, Rowbottom JR, Reynolds JD, et al. The AccuCath intravenous catheter system with retractable coiled tip Guidewire and conventional peripheral intravenous catheters: a prospective, randomized, controlled comparison. JAVA 2014;19:94-102.

13 Chick JFB, Reddy SN, Chen JX, et al. A randomized comparison between an intravenous catheter system with a retractable guidewire and conventional intravenous catheters. J Vasc Access 2017;18:530-4.

14 Stone BA. Ultrasound guidance for peripheral venous access: a simplified seldinger technique. Anesthesiology 2007;106:195.

15 Jin LM, Medeck S, Ruley J, et al. "Guidewire intravenous catheter systems do not improve first-pass success rates for peripheral access when placed by army combat medics (68W) in a pre-hospital setting." a prospective, randomized controlled trial with crossover study design. Mil Med 2018;183:e730-4.

16 Montrief T, Ramzy M, Long B. Micropuncture kits for difficult vascular access. Am J Emerg Med 2021;46:651-2. 
Copyright 2021 BMJ Publishing Group. All rights reserved. For permission to reuse any of this content visit https://www.bmj.com/company/products-services/rights-and-licensing/permissions/

BMJ Case Report Fellows may re-use this article for personal use and teaching without any further permission.

Become a Fellow of BMJ Case Reports today and you can:

- Submit as many cases as you like

Enjoy fast sympathetic peer review and rapid publication of accepted articles

Access all the published articles

Re-use any of the published material for personal use and teaching without further permission

Customer Service

If you have any further queries about your subscription, please contact our customer services team on +44 (0) 2071111105 or via email at support@bmj.com.

Visit casereports.bmj.com for more articles like this and to become a Fellow 